Supplemental Information

for

\title{
Sry-Directed Sex Reversal in Transgenic Mice is Robust to Enhanced DNA Bending: Comparison of Human and Mouse Murine HMG Boxes
}

Nelson B. Phillips, Tatiana Nikolskaya, Agnes Jancso-Radek, Varda Ittah, Fashun Jiang, Rupinder Singh, Elisha Haas, \& Michael A. Weiss

\section{Table of Contents}

Purpose of Supplement. .............................. 2

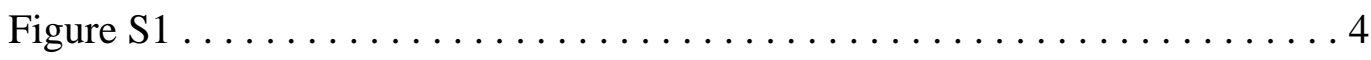

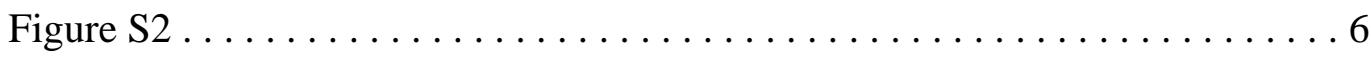

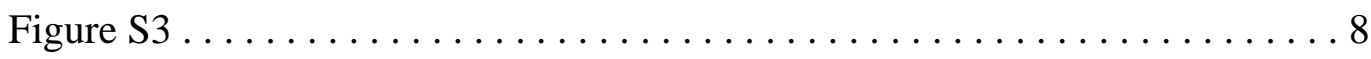

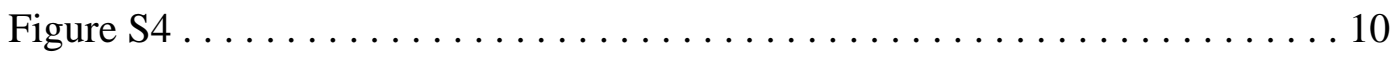

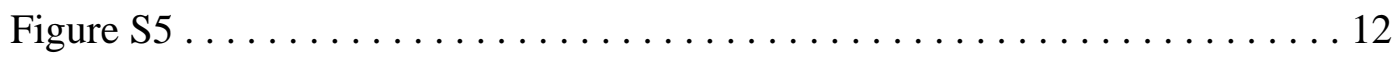

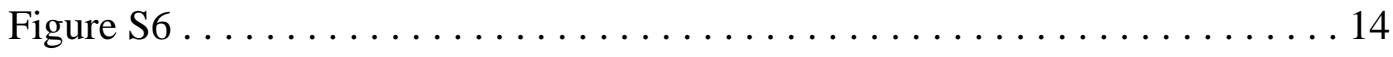

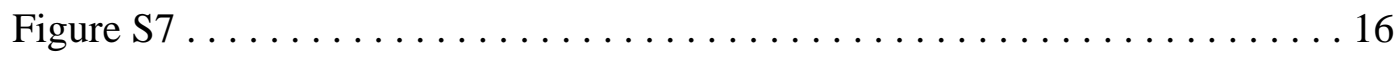

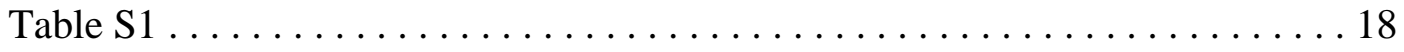

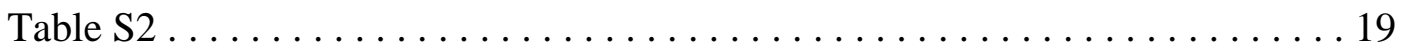

Table S3 .................................... 21

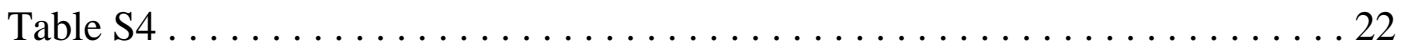




\section{Purpose of Supplement}

This supplement contains seven figures and four supplemental tables. Figure S1 demonstrates that the specific DNA binding affinity of the murine SRY HMG box is not affected by the C41S substitution on the back surface of the HMG box. The substitution also does not affect specific DNA bending as probed by PGE (see Fig. 5 in main text) or by steady-state FRET (not shown). In Figure S2 are shown far-UV CD spectra of the human SRY domain, murine SRY domain, and C41S murine analogue; similar helix-rich patterns are observed in each case. Figure S3 demonstrates that the PGE-detected DNA bend angle on binding of the human SRY HMG box is similar to that observed on binding of intact human SRY. Figures S4-S6 provide additional 1H-NMR spectra showing slow-exchange between bound and free DNA sites (Fig. S4), NOEs between imino protons (Fig. S5), and NOEs from imino protons to other DNA (and possible protein) resoances (Fig. S6). Finallly, a structural model of the I13 cantilever insertion site is shown in stereo in Figure S7; coordinates were obtained from G. M. Clore and colleagues (Protein Data Bank identifier 1J46).

In Table S1 are given the chemical shifts of the imino resonances of the human and murine protein-DNA complexes in relation to the free DNA. Table S2 provides a summary of previous PGE studies of murine SRY. These studies employed a variety of different protein fragments, DNA sequences, and gel compositions, all of which can influence the apparent DNA bend angles. Interpretation of side-by-side comparison of the murine and human HMG boxes by Grosschedl and coworkers (Giese, K. et al. Proc. Natl. Acad. Sci USA 91, 3368-3372) is complicated in retrospect by vector-derived substitutions in their protein constructs (see Discussion in text). Table S3 are the details 
of the steady-state anisotropy measurements. Table S4 provides selected interproton distances at the cantilever insertion site of the Clore structure of an hSRY-DNA complex. 
Figure S1. CD spectra of SRY HMG boxes demonstrate similar secondary structures. Color code: hSRY (black line), mSRY (filled circles), and C41S mSRY analogue (red cicles). Spectra were obtained at $4{ }^{\circ} \mathrm{C}$ in a buffer consisting of $140 \mathrm{mM} \mathrm{KCl}$ and $10 \mathrm{mM}$ potassium phosphate ( $\mathrm{pH}$ 7.4). Thermodynamic parameters of unfolding and denaturation temperatures are given in Table 1 (main text). 


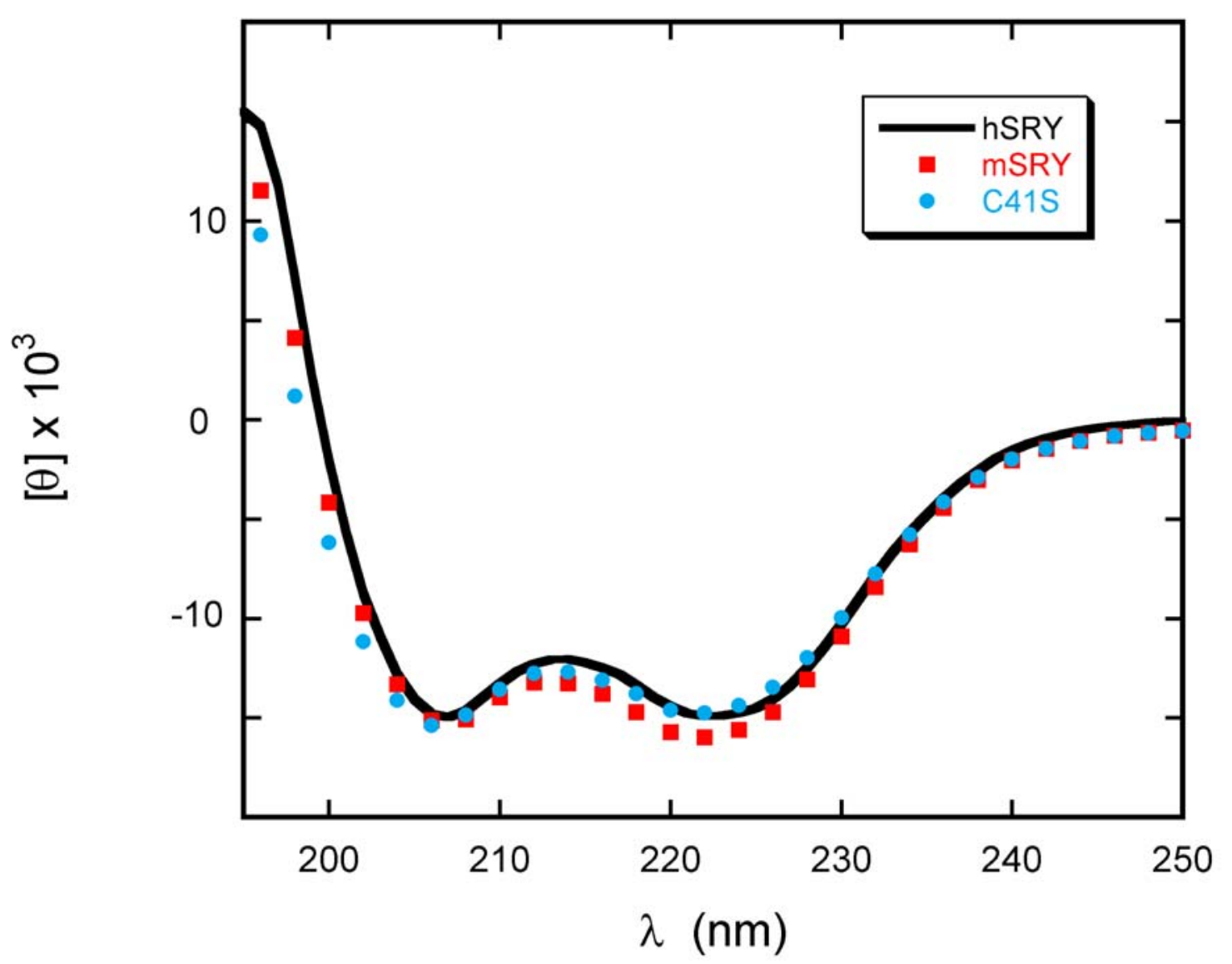

Figure S1 
Figure S2. GMSA DNA-Binding Assay. The substitution C41S has no detectable effect on the affinity of the mSRY domain for a consensus 5'-ATTGTT DNA site. GMSA used a 36mer SRY target DNA duplex CATACTGCGGGGGTGATTGTTCAGGATCATACTGCG-3' and complement) containing the underlined consensus SRY binding sequence probed with the HMG box of both C41S mSRY and mSRY. Protein samples were reconstituted in incubation buffer (140 mM KCl, 20 mM Tris-HCl pH 7.4, 5 mM MgCl 2,1 ng/ul poly dIdC, 4 mM DTT, 33 $\mathrm{ug} / \mathrm{ml} \mathrm{BSA}$, and $8 \%$ glycerol) containing the $\gamma_{-}^{33} \mathrm{P}$ labeled DNA probe. DNA probe concentration was $<1 \mathrm{nM}$ in each case. Samples were incubated on ice for one hour before loading onto $8 \%$ native polyacrylamide gels containing $0.45 \mathrm{X}$ TB buffer. Gels were run for 1 -2 hours at $4^{\circ} \mathrm{C}$ and $20 \mathrm{~V} / \mathrm{cm}$, dried, and exposed overnight and images were visualized using a Typhoon phosphorimager system (Molecular Dynamics). Relative band intensities were quantitated using ImageQuant v 5.2 software (Molecular Dynamics). (A) Lanes a and $\mathrm{h}$ contain free 36mer duplex without protein. Lanes b-g contain increasing concentrations of $\operatorname{mSRY}(10,20,40,80,160$ and $320 \mathrm{nM})$. Lanes i-n contain increasing concentrations of mSRY C41S (8.5, 17, 34, 68, 136, and $272 \mathrm{nM})$. C1 indicates 1:1 mSRY to DNA complex. Other higher order species are also seen in this gel $(\mathrm{C} 2, \mathrm{C} 3)$. (B) Binding curve comparing binding of mSRY C41S and mSRY to the 36mer DNA duplex probe. The fitted curve represents the average of 5 separate GMSA experiments with standard deviation represented as error bars. 


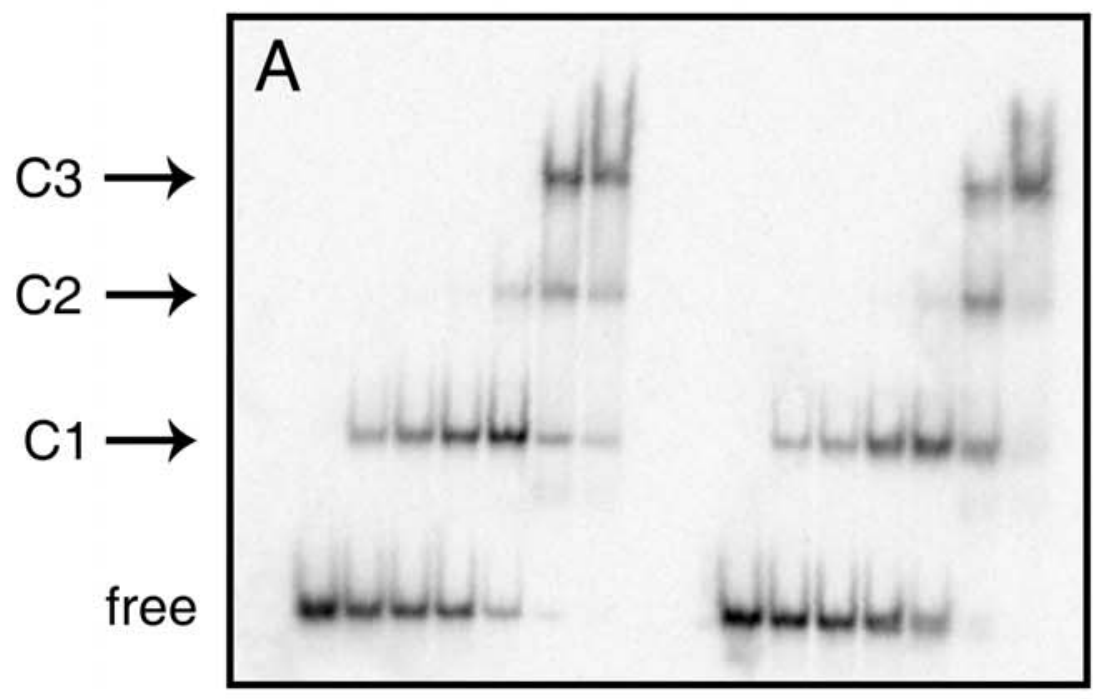

$\underset{\text { wild-type mSRY }}{\mathrm{a} \mathrm{b} \mathrm{c} \mathrm{d} \mathrm{e} \mathrm{f} \mathrm{g}} \frac{\mathrm{h} \mathrm{i} \mathrm{j} \mathrm{k} \mathrm{I} \mathrm{m} \mathrm{n}}{\mathrm{C} 41 \mathrm{~S} \text { mSRY }}$

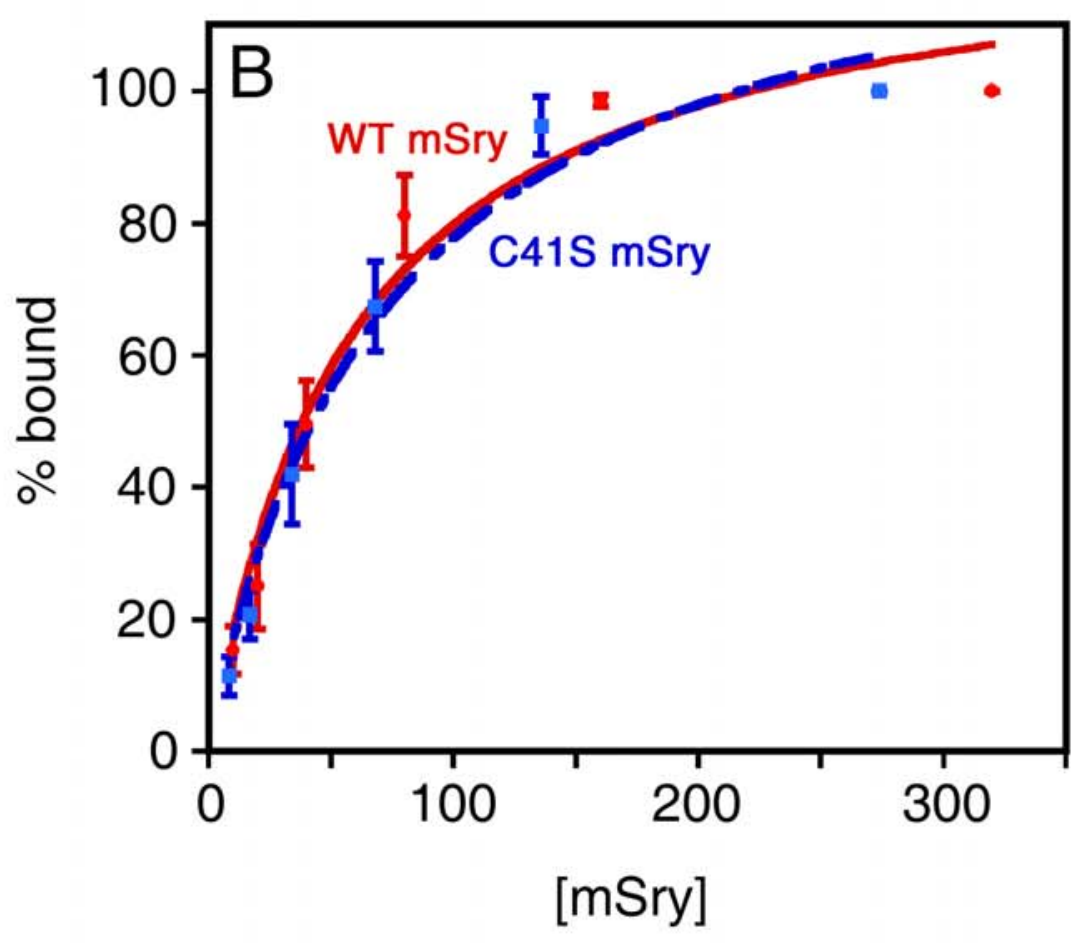

Figure S2 
Figure S3. PGE Analysis of DNA Bending of intact hSRY and isolated HMG box.. The inferred DNA bend angle for intact SRY is similar to that observed in studies of the isolated HMG box. (A) Permutation gel electrophoresis and (B) plot of relative electrophoretic mobility as function of flexure displacement in DNA probes. Binding of full-length human SRY is shown in left-hand portion of panel A (filled triangles in panel B); binding of domain containing HMG box and basic tail ( 86 residues) is shown in righthand portion (open circles in B). Studies employed DNA site 5'-

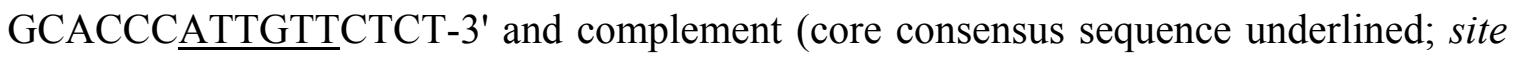
2, designated TRC-11 by Grosschedl and coworkers (Giese, K. et al. Genes Dev. 9, 9951008)). Inferred DNA bend angles with intact SRY or isolated HMG domain are $69.2^{\circ} \pm$ $1^{\circ}$ and $69.7^{\circ} \pm 1^{\circ}$, respectively, in this gel system $(6.5 \%$ polyacrylamide with $29: 1$ ratio of acrylamide:bis-acrylamide at $4{ }^{\circ} \mathrm{C}$ ). These estimates differ somewhat from values in Table 3 (main text) due to differences in gel composition. 

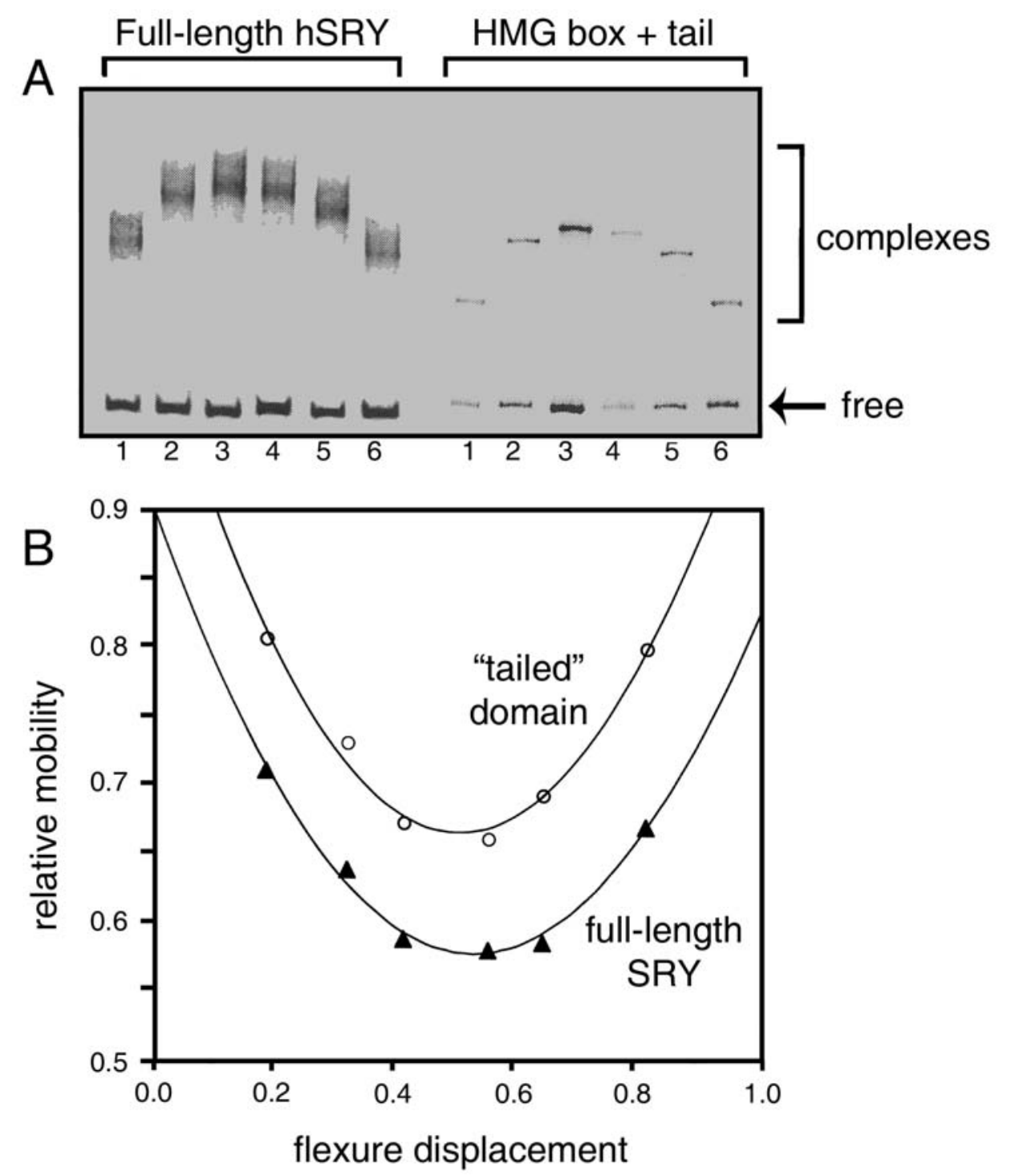

Figure S3 
Figure S4. Slow exchange between bound and free DNA sites is observed upon titration of mSRY HMG box. (A-E) Successive addition of protein to achieve protein-DNA stoichiometries of 1:5 (A), 2:5 (B), 3:5 (C), $4: 5$ (D) and 5:5 (E). Arrows in panel B indicate bound-state resonances. Spectra were acquired at $400 \mathrm{MHz}$ and $25{ }^{\circ} \mathrm{C}$ as described in text. The DNA concentration at the start of the titration was $1.5 \mathrm{mM}$. Similar spectra in slow exchange have been described in studies of the human SRY HMG box with the same 15-base-pair DNA site (King, C. Y. et al. Proc. Natl. Acad. Sci. USA 90, 11990-11994). 

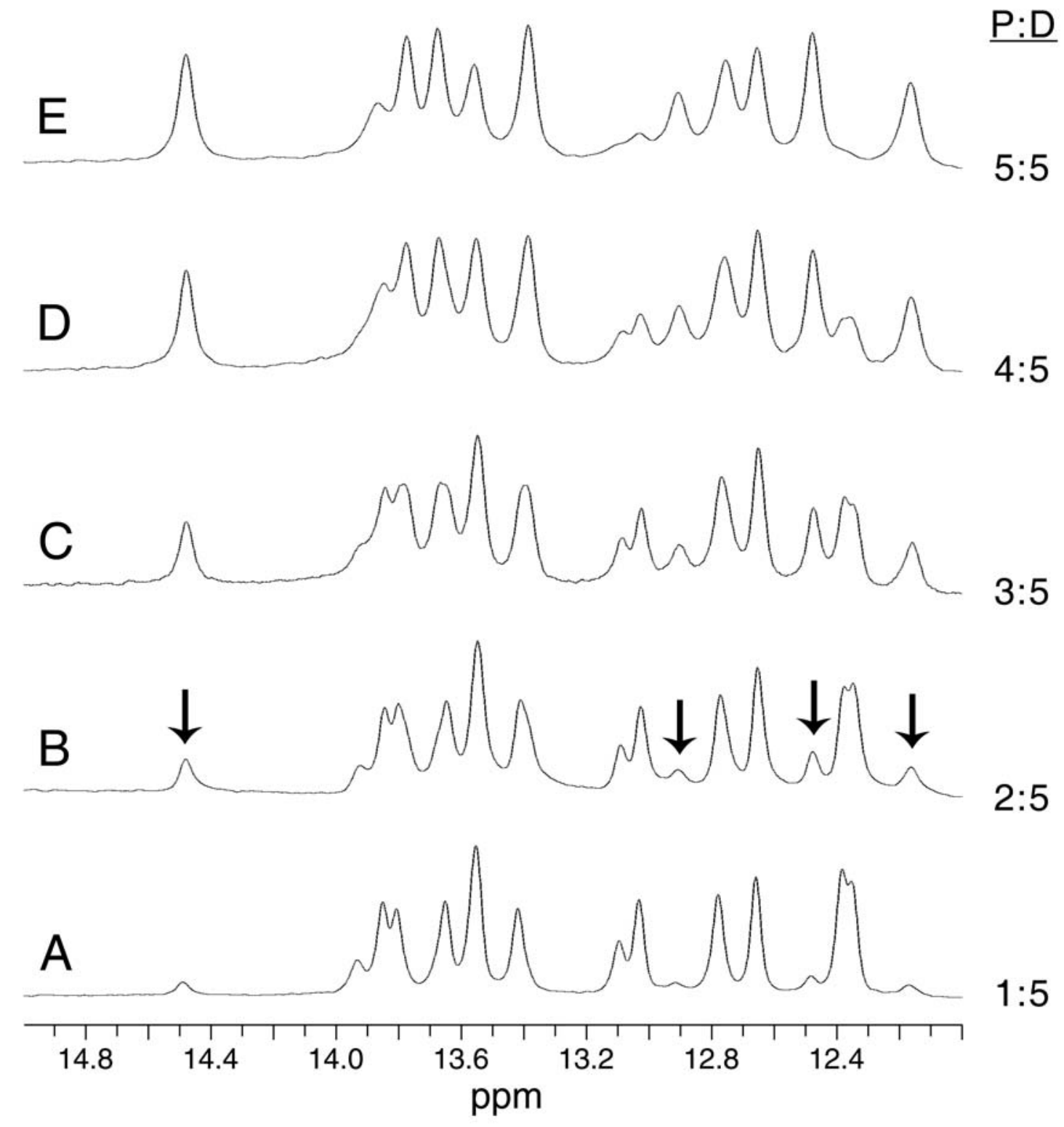

Figure S4 
Figure S5. NOESY spectrum of 1:1 mSRY-DNA complex showing NOEs between imino protons of Watson-Crick DNA base pairs: (A) 2D spectrum and (B) selected side chains to illustrate signal-to-noise ratios. Whereas NOEs between successive base pairs are ordinarily observed in the double helix, partial intercalation of M13 "cantilever" side chain is associated with absence of inter-imino NOE between T8 and T9 (empty boxes). Other NOEs are as labeled. Slices in panel B were extracted at $\omega_{1}$ frequencies corresponding to the imino resonances of G10 (top), T8, G13, T9, and T11 (bottom). Inset spectra are enlarged four-fold in gain to illustrate noise level. Empty boxes indicate positions of missing T8-T9 NOE centered at arrows. Arrows indicate absences of T8-T9 NOE. Slanted arrow in T8 slice indicates position of putative 8-9 cross peak at the downslope of noise peak (in successive slices there is no bone fide cross peak). Spectrum was acquired in $90 \% \mathrm{H}_{2} \mathrm{O}$ at $500 \mathrm{MHz}$ and $25{ }^{\circ} \mathrm{C}$ as described in text. The mixing time was $75 \mathrm{~ms}$. The DNA site contains 15 base pairs as described in text. Similar spectra of human complex have been described (King, C. Y. et al. Proc. Natl. Acad. Sci. USA 90, 11990-11994). 

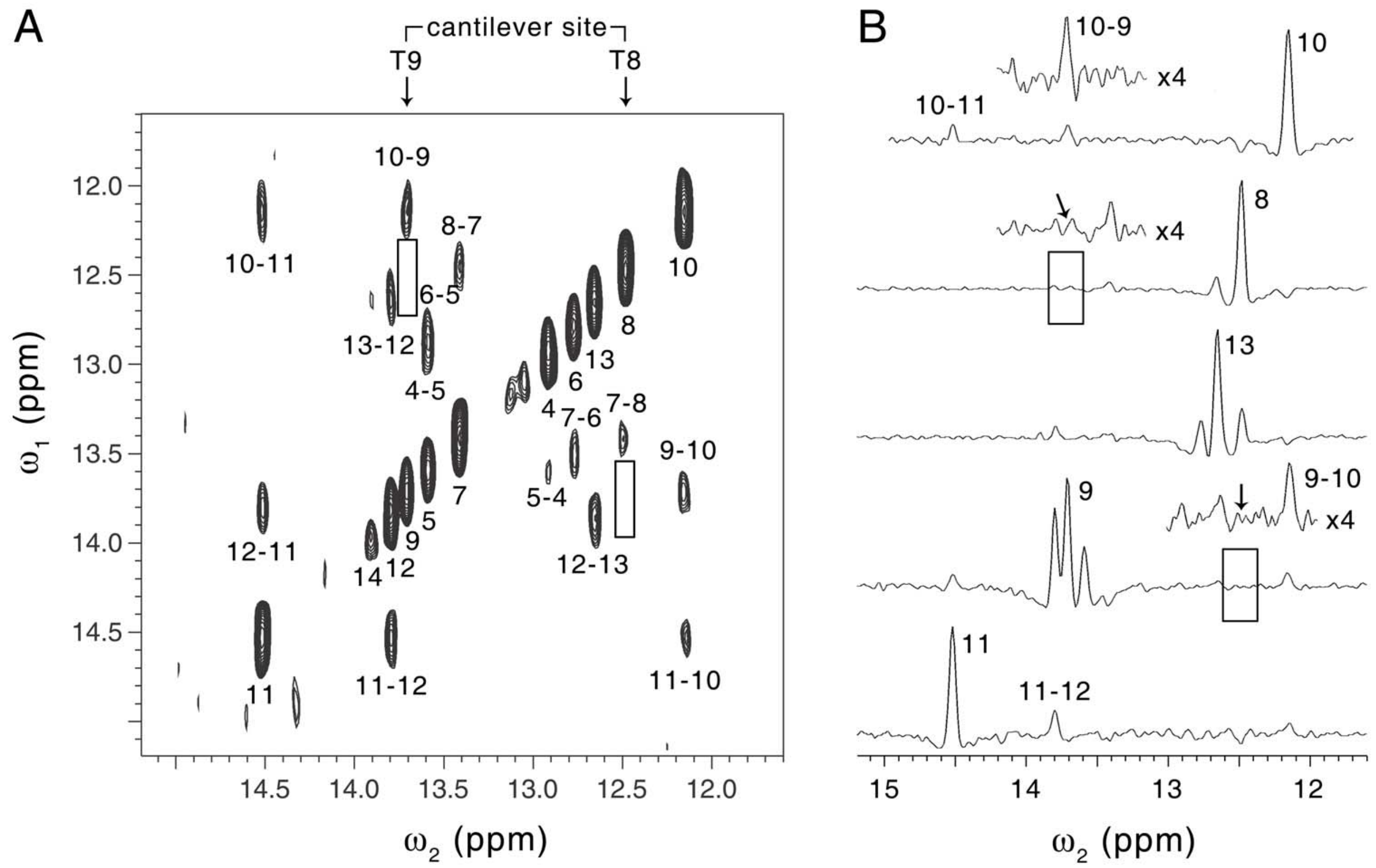

Figure S5 
Figure S6. Comparison between NOESY spectra at $15^{\circ} \mathrm{C}$ of human (A) and murine (B) SRY-DNA complexes showing NOEs between imino DNA protons (vertical axis; $\omega_{2}$ ) and neighboring protons in DNA and protein (horizontal axis; $\omega_{1}$ ). Adenine $\mathrm{H} 2$ resonances exhibit similar but not identical chemical shifts in the two complexes. No NOEs are observed between T8 H3/A9 H2 or T9 H3/A8 H2. (This conclusion is in accord with analysis of the symmetry-related region of the spectrum, which exhibits enhanced digital resolution among $\mathrm{H} 2$ resonances.) Because the $\mathrm{H} 2$ resonances of $\mathrm{A} 8$ and $\mathrm{A} 9$ exhibit similar chemical shifts, a putative A8-A9 NOE would lie close to the diagonal and would be difficult to observe in homonuclear 2D spectra. 


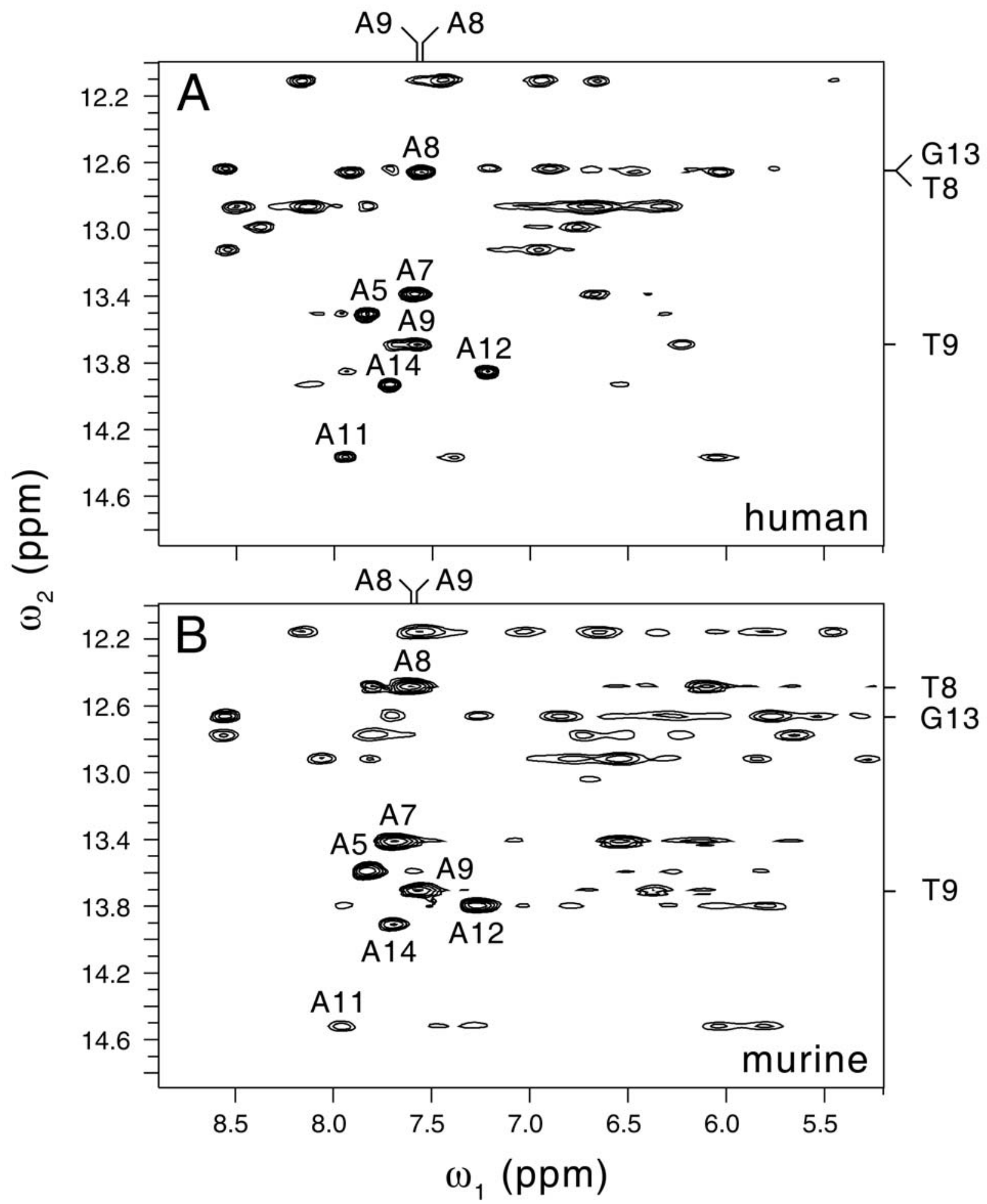

Figure S6 
Figure S7. Molecular model of cantilever insertion site in NMR structure of the human SRY-DNA complex as determined by G. M. Clore and coworkers (Murphy, E. C. et al. J. Mol. Biol. 312, 481-499). Protons are color-coded as shown. Key inter-proton distances are given in Table S4. 

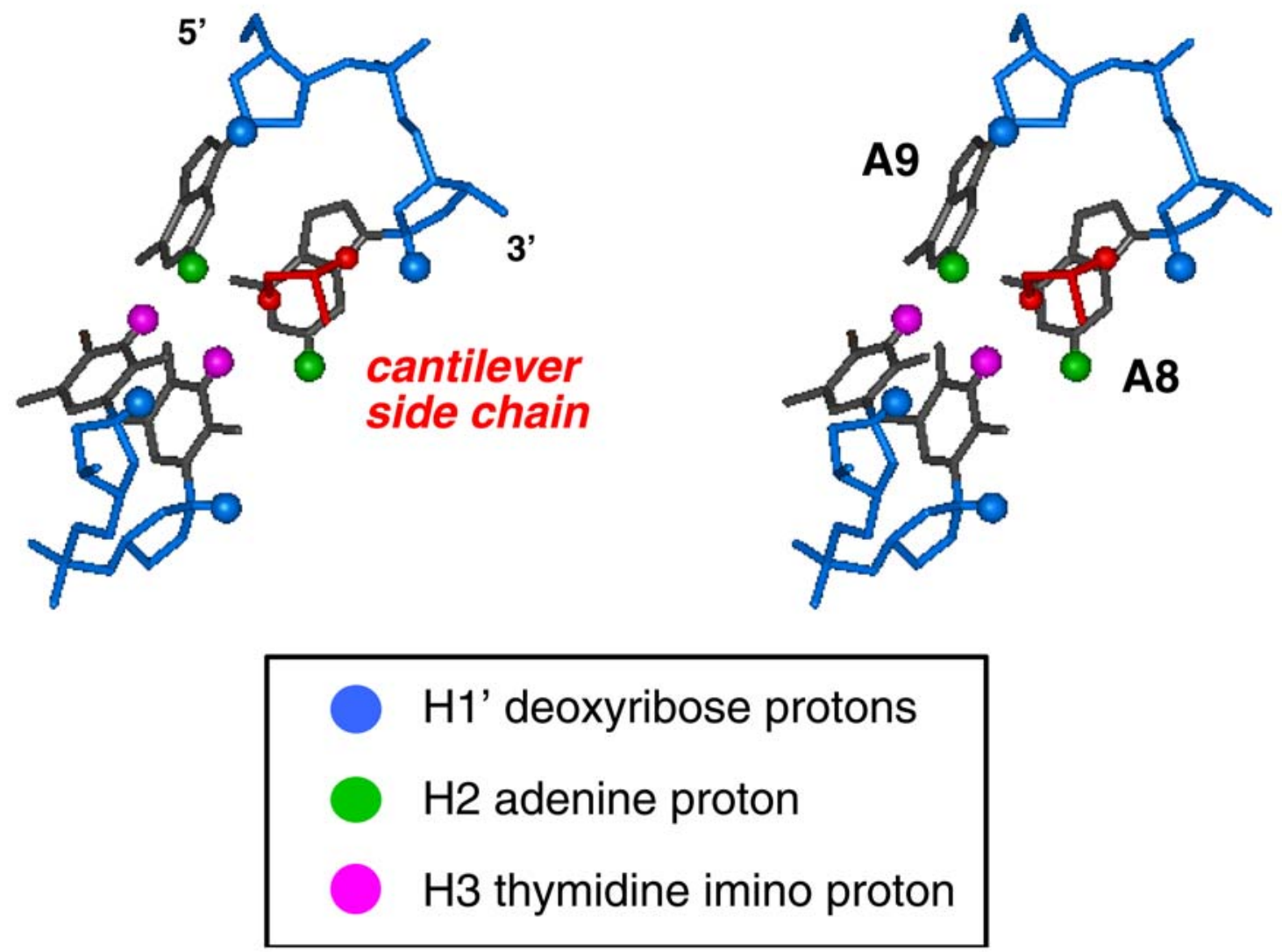

Figure S7 
Table S1. Imino ${ }^{1} \mathrm{H}-\mathrm{NMR}$ Chemical Shifts

\begin{tabular}{lcccccc}
\hline base pair & free & human & $\Delta \delta_{\text {hum }}$ & murine & $\Delta \delta_{\text {mur }}$ & $\Delta \Delta \delta$ \\
\hline 2 & 13.11 & - & - & 13.16 & 0.05 & - \\
3 & 13.01 & 13.17 & 0.16 & 13.09 & 0.08 & 0.08 \\
4 & 12.76 & 13.02 & 0.26 & 12.94 & 0.18 & 0.08 \\
5 & 13.53 & 13.55 & 0.02 & 13.62 & 0.09 & -0.07 \\
7 & 12.33 & 12.90 & 0.57 & 12.81 & 0.48 & 0.09 \\
8 & 13.46 & 13.43 & -0.03 & 13.45 & -0.01 & -0.02 \\
9 & 13.69 & 12.71 & -0.98 & 12.51 & -0.82 & -0.16 \\
10 & 13.55 & 13.72 & 0.18 & 13.85 & 0.40 & -0.03 \\
11 & 12.32 & 12.16 & -0.16 & 12.16 & -0.16 & 0.00 \\
12 & 13.84 & 14.40 & 0.56 & 14.56 & 0.72 & -0.16 \\
13 & 13.99 & 13.89 & -0.10 & 13.82 & -0.10 & 0.07 \\
14 & 12.67 & 12.69 & 0.02 & 12.68 & 0.01 & 0.01 \\
\hline & 13.85 & 13.96 & 0.11 & 13.95 & 0.10 & 0.01 \\
\hline
\end{tabular}

NMR studies employed DNA duplex 5'-GGGGTGATTGTTCAG-3' and complement (inset in Fig. 8A; site 1 in DNA bending studies in Table 3). Numbering scheme refers to top strand; primes (e.g., $\left.7^{\prime}\right)$ refers to nucleoside of partner strand. Chemical shifts are given in parts per million ( $\mathrm{ppm}$ ) relative to DSS, assumed to be at $0 \mathrm{ppm}$. Positive values of $\Delta \delta$ indicate upfield shifts in complex (i.e., to lower ppm values); negative values represent downfield shifts. 
Table S2. Previous Electrophoretic Studies of DNA Bending Induced by Human and Murine SRY

\begin{tabular}{lllclll}
\hline DNA site & protein & gel & probe (bp) & angle & method & ref \\
\hline 5'-ccATTGTTct-3' & mSRY-p* & ND & 440 & $85^{\circ}$ & T-L & a \\
5',-gcATTGTTct-3' & hSRY & $6.5 \%$ & 141 & $83^{\circ}$ & F-B & b \\
5'-gcATTGTTct-3' & mSRY-p* & $10 \% / 29: 1$ & 100 & $80^{\circ}$ & T-L & c \\
5'-ccATTGTTct-3' & hSRY-p* & ND & 440 & $60^{\circ}$ & T-L & d \\
5'-ccATTGTTct-3' & mSRY-p* & ND & 440 & $85^{\circ}$ & T-L & d \\
5'-ccATTGTTgc-3' & hSRY-p* & ND & 440 & $30^{\circ}$ & T-L & d \\
5' 'ccATTGTTgc-3' & mSRY-p* & ND & 440 & $60^{\circ}$ & T-L & d \\
5'-ccATTGTTct-3' & hSRY-p & $10 \%$ & 141 & $89^{\circ}$ & F-B & e
\end{tabular}

ND, gel composition was not described. Protein fragments: hSRY, full-length human SRY; mSRY-p*, variant murine domain containing vector-derived substitutions in C-terminal tail (underlined in HRRAKVNSS; residues 77-85 in HMG box); SRY-p*, variant human domain containing non-native substitutions in N-terminal segment and tail (underlined in RRKAKMLNSS; residues 77-86 in HMG box); and SRY-p 2 (residues 2-81 with longer but incomplete tail). Domain boundaries in SRY are defined relative to an HMG-box consensus (Werner, H. M., et al. (1995) Cell 81, 705-14). Algorithms employed to estimate DNA bend angles based on flexure displacement in PGE data are described by (T-L) Thompson and Landy (Thompson, J. F., et al. (1988) Nucleic Acids Res. 16, 9687-9705.) and (F-B) Bianchi, Ferrari and colleagues (Ferrari, S., et al. (1992) EMBO J. 11, 4497-4506).

a. Giese, K., Cox, J., and Grosschedl, R. (1992) Cell 69, 185-195.

b. Ferrari, S., Harley, V. R., Pontiggia, A., Goodfellow, P. N., Lovell-Badge, R., and Bianchi, M. E. (1992) EMBO J. 11, 4497-4506. 
c. Chow, C. S., Whitehead, J. P., and Lippard, S. J. (1994) Biochem. 33, 1512415130.

d. Giese, K., Pagel, J., and Grosschedl, R. (1994) Proc. Natl. Acad. Sci. U. S. A. 91, 3368-3372.

e. Pontiggia, A., Whitfield, S., Goodfellow, P. N., Lovell-Badge, R., and Bianchi, M.

E. (1995) Gene 154, 277-280. 
Table S3. Steady-state anisotropy of the probes bound to the pentadecamer oligonucleotides in three states: free DNA, DNA complexes of hSRY and mSRY .

\begin{tabular}{|c|c|c|}
\hline Sample & Donor anisotropy $^{\mathrm{b}}$ & Acceptor anisotropy $^{\mathrm{c}}$ \\
\hline $\begin{array}{l}\text { Single labeled DNA no } \\
\text { SRY }\end{array}$ & 0.11 & 0.23 \\
\hline $\begin{array}{l}\text { Single labeled DNA-hSRY } \\
\text { complex }\end{array}$ & 0.14 & 0.26 \\
\hline $\begin{array}{l}\text { Single labeled DNA- } \\
\text { mSRY complex }\end{array}$ & 0.14 & 0.25 \\
\hline Free DNA double labeled & 0.13 & 0.24 \\
\hline $\begin{array}{l}\text { Double labeled DNA- } \\
\text { hSRY complex }\end{array}$ & 0.17 & 0.26 \\
\hline $\begin{array}{l}\text { Double labeled DNA- } \\
\text { mSRY complex }\end{array}$ & 0.17 & 0.26 \\
\hline \multicolumn{3}{|c|}{$\begin{array}{l}{ }^{\mathrm{a}} \text { All measurements were carried out at } 4{ }^{\circ} \mathrm{C} \text { with excitation bandwidth } 0.5 \mathrm{~nm} \text { and } \\
\text { emission bandwidth } 3 \mathrm{~nm} \text {, error range } \pm 0.005 \text {. }{ }^{\mathrm{b}} \text { excitation wavelength } 490 \mathrm{~nm} \text {, emission }\end{array}$} \\
\hline
\end{tabular}


Table S4. Selected Inter-Proton Distances at Cantilever Insertion Site

\begin{tabular}{llcllc}
\hline proton 1 & proton 2 & distance $(\AA)$ & Proton 1 & Proton 2 & distance $(\AA)$ \\
\hline $\mathrm{T}_{8}, \mathrm{H} 3$ & $\mathrm{~T}_{9}, \mathrm{H} 3$ & 3.4 & $\mathrm{~T}_{9} \mathrm{H} 3$ & $\mathrm{~T}_{9} \mathrm{H} 1$ & 4.4 \\
$\mathrm{~T}_{8}, \mathrm{H} 3$ & $\mathrm{~T}_{8}, \mathrm{H} 1$ & 4.6 & $\mathrm{~T}_{9} \mathrm{H} 3$ & $\mathrm{~T}_{8} \mathrm{H} 1$ & 6.4 \\
$\mathrm{~T}_{8}, \mathrm{H} 3$ & $\mathrm{~A}_{8} \mathrm{H} 2$ & 3.0 & $\mathrm{~T}_{9} \mathrm{H} 3$ & $\mathrm{~A}_{9} \mathrm{H} 2$ & 2.8 \\
$\mathrm{~T}_{8}, \mathrm{H} 3$ & $\mathrm{~A}_{9} \mathrm{H} 2$ & 4.9 & $\mathrm{~T}_{9} \mathrm{H} 3$ & $\mathrm{~A}_{8} \mathrm{H} 2$ & 5.4 \\
$\mathrm{~T}_{8}, \mathrm{H} 3$ & $\mathrm{~A}_{9} \mathrm{H} 1$ & 6.4 & $\mathrm{~T}_{9} \mathrm{H} 3$ & $\mathrm{I}_{3} 13 \delta \mathrm{CH}_{3}$ & 4.2 \\
$\mathrm{~T}_{8} \mathrm{H} 3$ & $\mathrm{I} 13 \delta \mathrm{CH}_{3}$ & 4.3 & $\mathrm{~A}_{9} \mathrm{H} 2$ & $\mathrm{~A}_{8} \mathrm{H}_{2}$ & 5.5 \\
$\mathrm{~A}_{8} \mathrm{H} 3$ & $\mathrm{I} 13 \delta \mathrm{CH}_{3}$ & 3.5 & $\mathrm{~A}_{9} \mathrm{H} 2$ & $\mathrm{I}_{2} \delta \mathrm{CH}_{3}$ & 2.6 \\
\hline
\end{tabular}

Coordinates of hSRY-DNA complex were obtained from the Protein Data Bank (identifier 1J46). Adenosines 8 and 9 correspond to residues B109 and B108, respectively. Thymidines 8 and 9 refer to residues C120 and C121, respectively. This base-pair step in the hSRY-DNA complex is illustrated in Figure S7. 